Volume: 1, Issue: 2, June 2016, Pages: 34-39, DOI: http://dx.doi.org/10.19082/ah34

\title{
RELATIONSHIP AMONG PATHOPHYSIOLOGY OF GESTATIONAL DIABETES, PREECLAMPSIA, VITAMIN D LEVEL, AND IMMUNOMODULATION: A NARRATIVE REVIEW
}

\author{
Shima Mohiti ${ }^{1}$, Fatemeh Tara ${ }^{2}$, Hamid Reza Rahimi ${ }^{3}$
}

1: M.D., Resident of Obstetrics \& Gynecology, Women's Health Research Center, Department of Obstetrics \& Gynecology, School of Medicine, Mashhad University of Medical Sciences, Iran

2: M.D., Associate Professor, Department of Obstetrics \& Gynecology, School of Medicine, Mashhad University of Medical Sciences, Iran

3: M.D., Ph.D. of Molecular Medicine, Assistant Professor, Department of Modern Sciences and Technology, School of Medicine, Mashhad Univeristy of Medical Sciences, Mashhad, Iran

\section{TYPE OF ARTICLE: REVIEW}

\begin{abstract}
Context: Preeclampsia is among the major causes of maternal, fetal, and neonatal morbidity and mortality, worldwide. It is characterized by an increase in blood pressure and proteinuria (Systolic BP $\geqslant 140$ or Diastolic BP $\geqslant 90 \mathrm{mmHg}$ ). The serum level of 25 -hydroxy vitamin $\mathrm{D}$ deficiency has long been suspected as a risk factor for gestational diabetes mellitus (GDM) and preeclampsia, and perhaps 1,25-dihydroxy vitamin D has a role in the regulation of the immune system. Inflammatory markers, including cytokines, angiogenic factors, leukocytes, interleukins, and acute phase reactants, are involved in the pathophysiology of preeclampsia and gestational diabetes mellitus.

Objective: This review article was performed with the aim to assess the relationship among pathophysiology of gestational diabetes, preeclampsia, vitamin D level, and immunomodulation.

Evidence Acquisition: Databases of Cochrane (2000-2016), Embase (2000-2016), Pubmed/Medline (1995-2016), and Google Scholar (2000-2016) were searched to find the related references with keywords of gestational diabetes mellitus, preeclampsia, vitamin $\mathrm{D}$, regulation of the immune system. The contents of the articles were exactly and repeatedly studied and analyzed.

Results: Vitamin D deficiency is more prevalent in patients with gestational diabetes mellitus and preeclampsia than normal pregnant women are, so vitamin D supplementation may control glucose levels and blood pressure and improve the outcome of pregnancy.

Conclusion: Several studies, materials provided in this study, and clinical evidence confirm that both preeclampsia and gestational diabetes unbalance the maternal immune system; in addition, evidence from casecontrol studies show that vitamin D levels are significantly lower in patients with preeclampsia and diabetes than normal people.

KEYWORDS: Gestational diabetes mellitus, Preeclampsia, Vitamin D, Regulation of immune system
\end{abstract}

\section{CONTEXT}

Diabetes is the most common medical problem in pregnancy (1). There are two types of gestational diabetes: pregestational diabetes, which is diagnosed before pregnancy, and gestational diabetes, which is diagnosed during the pregnancy (1). In 2006, 179,898 American women were reported with diabetes during the pregnancy, accounting for $4.2 \%$ of all live births (1). Some studies in recent years (2015) have reported $4.62 \%$ prevalence gestational diabetes (2). The risk of gestational diabetes is higher among African-American, native-American, Asian-American, and Spanish-American women than Caucasian women. Increased incidence of gestational pregnancy during the last 15 years signals the same trend in the incidence of obesity (1). On the other hand, the incidence rate of preeclampsia

\section{Correspondence:}

Assistant Professor Dr. Hamid Reza Rahimi, Department of Modern Sciences and Technology, School of Medicine, Mashhad Univeristy of Medical Sciences, Mashhad, Iran.

Tel: +98.5138002287, Fax:+98.5138002287, E-mail: Rahimihr891@mums.ac.ir

Received: February 20, 2016, Accepted: March 22, 2016, Published: June 2016

iThenticate screening: February 22, 2016, English editing: March 27, 2016, Quality control: March 28, 2016

(C) 2016 The Authors. This is an open access article under the terms of the Creative Commons Attribution-NonCommercialNoDerivs License, which permits use and distribution in any medium, provided the original work is properly cited, the use is non-commercial and no modifications or adaptations are made. 
has been reported as $2 \%-7 \%$ with greater prevalence among nulliparous women $(6 \%-7 \%)$. The neonatal consequence in patients with preeclampsia is mainly dependent on the gestational age at delivery. Women with maternal preeclampsia are prone to DIC, intracranial bleeding, renal failure, retinal detachment, pulmonary edema, liver rupture, placenta detachment, and death (1). It seems that endothelial cell dysfunction is the main cause of preeclampsia $(3,4)$; however, the exact mechanism that causes this disorder is not yet known. Inflammatory cells are activated in preeclampsia and move to the site of vascular injury. These cells are activated in preeclampsia and concentrated at the site of vascular injuries (5). Activation of these white cells is associated with increased serum level of proinflammatory molecules, cytokines, and adhesion molecules. Some studies have shown increased TNF- $\alpha$ and IL-6 plasma levels in preeclampsia (6-8). The development of preeclampsia may be due to increasing maternal inflammatory responses to pregnancy secondary to the compound of placental and maternal factors associated with the phenotype and genotype (9). This inflammatory response leads to a broader syndrome, including endothelial dysfunction, metabolic disorders, and thrombotic in preeclampsia. The aim of this narrative review is to assess the relationship among pathophysiology of gestational diabetes, preeclampsia, vitamin D level, and immunomodulation.

\section{EVIDENCE ACQUISITION}

Databases of Cochrane (2000-2016), Embase (2000-2016), Pubmed/Medline (1995-2016), and Google Scholar (2000-2016) were searched to find the related references with keywords of gestational diabetes mellitus, preeclampsia, vitamin D, regulation of the immune system. The contents of the articles were exactly and repeatedly studied and analysed.

\section{RESULTS}

\subsection{Vitamin D and Immune System}

The exact effects of vitamin D on the immune system's responses have been identified. Epidemiological evidence shows a certain relationship between vitamin D deficiency and greater incidence of autoimmune diseases. In addition, its pharmacologic role in regulating immune responses and its use in the treatment of diseases are obvious. An immunosuppression role also has been suggested for vitamin D in patients with rheumatoid arthritis (RA). Vitamin D has an important role in the treatment of patients with systemic lupus erythematosus (SLE) through reducing the activation of the immune system and the devastating effects of the disease. In general, vitamin D has an important direct and indirect role in differentiation and proliferation of CD4+ cells. This effect plays a part in autoimmune diseases (10). Several clinical studies have suggested that the serum level of vitamin D has a salient role in autoimmune disease in various populations of the world through increasing the prevalence of this disease. There is a correlation between reduced intake of vitamin D and increased the prevalence of the illness in such diseases as type I diabetes (IDDM), SLE, RA, MS (multiple sclerosis), and inflammatory bowel disease (IBD) (10). A 30-year study showed that the prevalence of type I diabetes was far lower in children with a higher intake of vitamin D (11). Four large case-control studies have proved that the intake of vitamin D can prevent the development of type I diabetes (12). In other words, vitamin D has a key role in natural killer cells (NK), cytotoxic $\mathrm{T}$ cells, and macrophages in regulating the immune system (11). Williams (1849) used fish oil (which is rich in vitamin D) for the treatment of $400 \mathrm{~TB}$ patients (12). Liu et al. (2006) highlighted the role of vitamin D in the acquired immune system by describing vitamin $\mathrm{D}$ function in the production of antimicrobial proteins against TB bacilli. Vitamin D acts against tuberculosis through TLR1 and TLR2 by inhibiting mycobacterium tuberculosis (11). In the acquired immune system, vitamin D inhibits the production of TH1 and increases the production of Th2. This shifts the immune system toward the humoral immune system rather than the cellular immune system; thus vitamin $\mathrm{D}$ has a significant effect in rheumatoid arthritis. Animal models have proved that the early use of vitamin D can be useful in treating rheumatic disease. Accordingly, vitamin D can regulate and modulate the immune system (11). Taking together, vitamin D has a regulatory effect on the immune system and thus can prevent the autoimmune diseases. This effect has been well established in the literature.

\subsection{Immune System and Preeclampsia}

Normal pregnancy is always associated with some degrees of mild systemic inflammation. The systemic inflammation has complicated effects on metabolism. The different components of an acute phase reaction can trigger these metabolic effects, including insulin resistance and hyperlipidemia. Tumour necrosis factor (TNF- $\alpha$ ) is among these factors. This cytokine causes insulin resistance, lipolysis, and lipogenesis inhibition as well as the elevation of serum free fatty acid concentrations. According to previous studies, preeclampsia increases the concentration of serum free fatty acids $(13,14)$. Several studies are going on into the role of genetic in developing preeclampsia. In one of these studies, a single nucleotide polymorphism in IL-10 gene promoter, which produces a certain genotype, decreases the risk of preeclampsia development by about 33\% (15). Injection of interleukin-10 
deficient to mice results in more severe symptoms, as compared with normal mice; in addition, all ranges of preeclampsia expressions can be found in an interleukin-10 deficient mouse, whereas only mild and relative signs are seen in normal mice. Indeed, interleukin-10 deficiency in the serum of infected patients results in disruption in the formation of paired helical artery, hypoxic damage to placenta and uterus, and increased production of Eng in mice, leading to the development of preeclampsia (16). Research by Farzadnia et al. on pregnant women with the various severity of preeclampsia resulted in the detection of hs-CRP in all samples. Findings showed that the patient with severe preeclampsia had far higher levels of hs-CRP than patients with mild preeclampsia and normal pregnant women, indicating a significant between-groups difference. This implies that preeclampsia is an inflammatory trend that severely stimulates the immune system $(17,18)$. Studies also show that the injection of TNF- $\alpha$ to pregnant mice increases blood pressure (19); in addition, TNF- $\alpha$ has a role in regulated transcription of platelet-derived growth factor (PDGF) and endothelin 1 (ET-1). Both of these factors lead to vasoconstriction, which can result in the occurrence of hypertension (high blood pressure) involved in preeclampsia $(20,21)$. A study conducted by Farzadnia et al. in Mashhad University of Medical Sciences on the genotypes of patients showed that the frequency of AA was significantly higher than GG in patients with preeclampsia (22). Moreover, a study conducted on the mouse cremaster muscle suggested that TNF- $\alpha$ protein resulted in protein leakage from small blood vessels (23). This process during preeclampsia is the cause of an important clinical manifestation (non-dependent systemic and localized edema), which occurs due to vascular leakage. This cytokine also decreases the dilating effect of acetylcholine on blood vessels (24). According to some studies, the serum levels of two inflammatory markers (namely, sICAM-1 and sVCAM-1) in women with a history of preeclampsia have been elevated (25). Previous studies conducted by the current research team showed that the level of this factor was significantly higher in patients with severe preeclampsia than patients with mild preeclampsia and normal pregnant women $(17,18)$. It seems that these two inflammatory markers indicate preeclampsia-induced endothelial dysfunction in previous pregnancies. In other words, no change in serum level of these two markers is seen in newly developed preeclampsia. Higher levels of these two markers may indicate that preeclampsia-induced endothelial dysfunction and cardiovascular complications are more severe (26). Although there is no clear evidence about the pathophysiology of preeclampsia, although it has been proven that the immune system is somehow associated with the disease, the basic and clinical studies showed the relation between excited immune system and the severity and early onset of the disease.

\subsection{Vitamin D and Gestational Diabetes}

Larijani et al. posited that the existing evidence suggests a correlation between vitamin D metabolism with development or worsening of diabetes. This cross-sectional study was conducted on 741 pregnant women visiting hospitals affiliated with the Tehran University of Medical Sciences. The screening test was a 1 hour GCT50gr with a glucose level of higher than $130 \mathrm{mg} / \mathrm{dl}$ as a threshold. In the case of test impairments, follow-up was done using 3 hour GTT100gr test according to the Carpenter and Coustan thresholds for diagnosis of gestational diabetes. In the single-variable analysis, there was a significant correlation between the insulin-resistance index and insulin sensitivity index with serum vitamin D levels $(\mathrm{p}=0.001)$. Moreover, the prevalence of gestational diabetes in women with vitamin $\mathrm{D}$ deficiency (less than $12.5 \mathrm{nmol} / \mathrm{dl}$ ) was higher than patient with normal vitamin $\mathrm{D}$ level. According to the authors of this study, the prevalence of vitamin D deficiency is higher among those with gestational diabetes than those with normal pregnancy, specifically in cases with severe vitamin D deficiency. Therefore, adequate intake of vitamin D may be effective in controlling blood sugar levels of pregnant women (27). In a study in Semnan, Rahbar et al. (2015) measured vitamin D levels in 8-12 week pregnant women and its correlation with fasting blood sugar (28). They observed $72 \%$ prevalence of vitamin D deficiency, out of which severe deficiency accounted for $7.16 \%$ of it, which was statistically correlated with abnormal fasting blood sugar level (28). Another study addressed the correlation of haemoglobin A1C levels and vitamin D during the third trimester of pregnancy, and the correlation of mother's age, race, body mass, and employment status with OGTT results. According to the author, vitamin D level has an indirect correlation with poor blood sugar control. In addition, the routine measurement should be administrated to all pregnant women at the time of diabetes screening or even prior to it in order to treat women with vitamin D deficiency (29). Akhlaghi et al. studied 130 pregnant women in Mashhad University of Medical Sciences and found a significant difference between the serum vitamin D levels of the control group and case group (containing patients with gestational diabetes) (30). Both descriptive and analytic studies proved that the vitamin $\mathrm{D}$ level in gestational diabetes is substantially lower than healthy controls.

\subsection{Vitamin D and Preeclampsia}

In a case-control study (2007), in which race, gestational age, educational level, pregnancy rate, BMI, and smoking status have been considered, blood samples of the control and preeclampsia groups were gathered at the same 
gestational age (31). In this study, the serum D $(\mathrm{OH}) 25$ levels, at pregnancy and prior to it, were measured, and it was observed that women with preeclampsia had lower serum $\mathrm{D}(\mathrm{OH}) 25$ levels than the control group during the early period of pregnancy. According to those researchers, the risk of preeclampsia increased by two times with vitamin D level reduction to 20ng/l (31). They thus concluded that maternal vitamin D deficiency might be an independent risk factor for preeclampsia and recommended the conduction of some studies on the effect of vitamin D supplementation during the early period of pregnancy for preventing preeclampsia and promoting neonates' health (31). Abedi et al. (2014) conducted a case-control study in Ahwaz on 59 preeclamptic pregnancies and 59 normal pregnancies. The authors found that vitamin D level was significantly lower in preeclamptic pregnancies and recommended the intake of 400IU/day vitamin D for pregnant women (32). In Mashhad, Ghomian et al. performed a case-control study on 160 subjects and concluded that, although vitamin D deficiency was observed in both groups, it was significantly higher in women with preeclampsia (33).

\section{CONCLUSIONS}

Several studies, materials provided in this study, and clinical evidence confirm that both preeclampsia and gestational diabetes unbalance maternal immune system; in addition, evidence from case-control studies show that vitamin D levels are significantly lower in patients with preeclampsia and diabetes than normal people (28-30, 32, 33). Other studies on other autoimmunity diseases suggest that the administration of a vitamin D supplement can regulate the immune system $(10,11)$. We are recommending performing a cohort study on vitamin $\mathrm{D}$ levels in pregnant women, in which these levels at the baseline are measured to find their correlation with the incidence and prevalence of preeclampsia and gestational diabetes. In the next stage, intervention studies should be done to examine the role of vitamin D supplementation in the incidence and prevalence of these diseases.

\section{ACKNOWLEDGMENTS:}

The Mashhad University of Medical Science Research Council supported this research. This paper is the subject thesis of Dr. Hamid Reza Rahimi, who is the Ph.D. candidate of molecular medicine.

\section{CONFLICT OF INTEREST:}

There is no conflict of interest to be declared.

\section{AUTHORS' CONTRIBUTIONS:}

All authors contributed to this project and article equally. All authors read and approved the final manuscript.

\section{REFERENCES:}

1) Cunningham F, Leveno K, Bloom S, Hauth J, Rouse D, Spong C. Williams Obstetrics: 23rd Edition. New york: McGraw-Hill Education; 2009. 597-624 p.

2) Meek CL, Lewis HB, Patient C, Murphy HR, Simmons D. Diagnosis of gestational diabetes mellitus: falling through the net. Diabetologia. 2015; 58(9): 2003-12. doi: 10.1007/s00125-015-3647-z. PMid: 26071759. PMCid: PMC4526580.

3) Dekker GA, Sibai BM. Etiology and pathogenesis of preeclampsia: current concepts. American journal of obstetrics and gynecology. 1998; 179(5): 1359-75. doi: 10.1016/S0002-9378(98)70160-7.

4) Roberts J, Taylor R, Musci T, Rodgers G, Hubel C, McLaughlin M. Preeclampsia: An endothelial cell disorder. International Journal of Gynecology \& Obstetrics. 1990; 32(3): 299. doi: 10.1016/00207292(90)90402-7.

5) Smith GC, Pell JP, Walsh D. Pregnancy complications and maternal risk of ischaemic heart disease: a retrospective cohort study of 129290 births. The Lancet. 2001; 357(9273): 2002-6. doi: 10.1016/S01406736(00)05112-6.

6) Greer IA, Lyall F, Perera T, Boswell F, Macara LM. Increased concentrations of cytokines interleukin-6 and interleukin-1 receptor antagonist in plasma of women with preeclampsia: a mechanism for endothelial dysfunction? Obstetrics \& Gynecology. 1994; 84(6): 937-40. PMid: 7526306.

7) Conrad KP, Miles TM, Benyo DF. Circulating levels of immunoreactive cytokines in women with preeclampsia. American Journal of Reproductive Immunology. 1998; 40(2): 102-11. doi: 10.1111/j.16000897.1998.tb00398.x. PMid: 9764352.

8) Vince GS, Starkey PM, Austgulen R, Kwiatkowski D, Redman CW. Interleukin - 6, turnour necrosis factor and soluble turnour necrosis factor receptors in women with pre - eclampsia. BJOG: An International Journal of Obstetrics \& Gynaecology. 1995; 102(1): 20-5.doi: 10.1111/j.1471-0528.1995.tb09020.x. 
9) Redman CW, Sacks GP, Sargent IL. Preeclampsia: an excessive maternal inflammatory response to pregnancy. American journal of obstetrics and gynecology. 1999; 180(2): 499-506. doi: 10.1016/S00029378(99)70239-5.

10) Deluca HF, Cantorna MT. Vitamin D: its role and uses in immunology. Faseb. 2001; 15(14): 2579-85. doi: 10.1096/fj.01-0433rev. PMid: 11726533.

11) Hewison M. Vitamin D and the immune system: new perspectives on an old theme. Rheum Dis Clin North Am. 2012; 38(1): 125-39. doi: 10.1016/j.rdc.2012.03.012. PMid: 22525848.

12) Kamen DL, Tangpricha V. Vitamin D and molecular actions on the immune system: modulation of innate and autoimmunity. J Mol Med (Berl). 2010; 88(5): 441-50. doi: 10.1007/s00109-010-0590-9. PMid: 20119827. PMCid: PMC2861286.

13) Borzychowski AM, Sargent IL, Redman CW. Inflammation and pre-eclampsia. Seminars in fetal \& neonatal medicine. 2006; 11(5): 309-16. doi: 10.1016/j.siny.2006.04.001. PMid: 16828580.

14) Redman CW, Sargent IL. Placental stress and pre-eclampsia: a revised view. Placenta. 2009; 30 Suppl A: S38-42.

15) de Groot CJ, Jansen MW, Bertina RM, Schonkeren JJ, Helmerhorst FM, Huizinga TW. Interleukin 102849AA genotype protects against pre-eclampsia. Genes and immunity. 2004; 5(4): 313-4. doi: 10.1038/sj.gene.6364092. PMid: 15085177.

16) Kalkunte S, Boij R, Norris W, Friedman J, Lai Z, Kurtis J, et al. Sera from preeclampsia patients elicit symptoms of human disease in mice and provide a basis for an in vitro predictive assay. The American journal of pathology. 2010; 177(5): 2387-98. doi: 10.2353/ajpath.2010.100475. PMid: 20889559. PMCid: PMC2966797.

17) Farzadnia M, Ayatollahi H, Hasan-Zade M, Rahimi HR. A comparative study of vascular cell adhesion molecule-1 and high-sensitive C-reactive protein in normal and preeclamptic pregnancies. Interventional medicine \& applied science. 2013; 5(1): 26-30. doi: 10.1556/IMAS.5.2013.1.5. PMid: 24265885. PMCid: PMC3831793

18) Farzadnia M, Ayatollahi H, Hasan-Zade M, Rahimi HR. A Comparative Study of Serum Level of Vascular Cell Adhesion Molecule-1 (sVCAM-1), Intercellular Adhesion Molecule-1(ICAM-1) and High Sensitive C - reactive protein (hs-CRP) in Normal and Pre-eclamptic Pregnancies. Iranian journal of basic medical sciences. 2013; 16(5): 689-93. PMid: 23826490. PMCid: PMC3700043

19) Alexander BT, Cockrell KL, Massey MB, Bennett WA, Granger JP. Tumor necrosis factor-alpha-induced hypertension in pregnant rats results in decreased renal neuronal nitric oxide synthase expression. American journal of hypertension. 2002; 15(2): 170-5. doi: 10.1016/S0895-7061(01)02255-5.

20) Hajjar KA, Hajjar DP, Silverstein RL, Nachman RL. Tumor necrosis factor-mediated release of plateletderived growth factor from cultured endothelial cells. The Journal of experimental medicine. 1987; 166(1): 235-45. doi: 10.1084/jem.166.1.235. PMid: 3598461.

21) Marsden PA, Brenner BM. Transcriptional regulation of the endothelin-1 gene by TNF-alpha. The American journal of physiology. 1992; 262(4): C854-61. PMid: 1566813.

22) Naderi M, Yaghootkar H, Tara F, Tavakkol Afshari J, Farid Hosseini R, Ghayour Mobarhan M, et al. Tumor necrosis factor-alpha polymorphism at position -238 in preeclampsia. Iranian Red Crescent medical journal. 2014; 16(1): e11195. doi: 10.5812/ircmj.11195. PMid: 24719701. PMCid: PMC3964419.

23) Anderson JA, Miller FN, Sims DE, Edwards MJ. Tumor necrosis factor causes microvascular protein leakage independently of neutrophils or mast cells. The Journal of surgical research. 1994; 56(6): 485-90. doi: 10.1006/jsre.1994.1078. PMid: 8015300.

24) Wang P, Ba ZF, Chaudry IH. Administration of tumor necrosis factor-alpha in vivo depresses endotheliumdependent relaxation. The American journal of physiology. 1994; 266(6): H2535-41. PMid: 8024016.

25) 1) Sattar N, Ramsay J, Crawford L, Cheyne H, Greer IA. Classic and novel risk factor parameters in women with a history of preeclampsia. Hypertension. 2003; 42(1): 39-42. doi: 10.1161/01.HYP.0000074428.11168.EE. PMid: 12743016.

26) Ramsay JE, Stewart F, Greer IA, Sattar N. Microvascular dysfunction: a link between pre-eclampsia and maternal coronary heart disease. BJOG: an international journal of obstetrics and gynaecology. 2003; 110(11): 1029-31. doi: 10.1111/j.1471-0528.2003.02069.x. PMid: 14592589.

27) Hossein-Nezhad A, Maghbooli J, Arzaghi S, Shafaei A, Rahmani M, Larijani B. Relation between vitamin D deficiency and gestational diabtes mellitus. Iranian Journal of Diabetes and Lipid Disorders. 2006; 5(3): 227-34. 
28) Rahbar N, Rajabi M, Mirmohammadkhani M. 25-hydroxy Vitamin D serum level in pregnant women with 8-12 gestational weeks in Semnan city and its association with Fasting Blood Sugar and Body Mass Index. The Iranian Journal of Obstetrics, Gynecology and Infertility. 2015; 18(167): 1-8.

29) Lau SL, Gunton JE, Athayde NP, Byth K, Cheung NW. Serum 25-hydroxyvitamin D and glycated haemoglobin levels in women with gestational diabetes mellitus. Medical Journal of Australia. 2011; 194(7): 334-7. PMid: 21470081.

30) Akhlaghi F, Bonakdaran S, Fijan A. Comparative study on serum level of vitamin D in women with gestational diabetes and normal pregnant women. Medical Journal of Mashhad University of Medical Sciences. 2014; 57(1): 429-35.

31) Bodnar LM, Catov JM, Simhan HN, Holick MF, Powers RW, Roberts JM. Maternal vitamin D deficiency increases the risk of preeclampsia. J Clin Endocrinol Metab. 2007; 92(9): 3517-22. doi: 10.1210/jc.20070718. PMid: 17535985. PMCid: PMC4288954.

32) Abedi P, Mohaghegh Z, Afshary P, Latifi M. The relationship of serum vitamin D with pre-eclampsia in the Iranian women. Matern Child Nutr. 2014; 10(2): 206-12. doi: 10.1111/mcn.12058. PMid: 23782626.

33) Ghomian N, Lotfalizade M, Movahedian A. Comparative study of serum level of vitamin D in pregnant women with preeclampsia and normal pregnant women. The Iranian Journal of Obstetrics, Gynecology and Infertility. 2015; 18(140): 1-6. 